\title{
Erratum to: Information Security Management \& Small Systems Security
}

\author{
Jan H.P. Eloff ${ }^{1}$, Les Labuschagne ${ }^{1}$, Rossouw von Solms ${ }^{2}$, and Jan Verschuren ${ }^{3}$ \\ 1 Rand Afrikaans University, South Africa \\ 2 Port Elizabeth Technikon, South Africa \\ ${ }^{3}$ Evaluation Centre for Instrumentation and Security Techniques, The Netherlands
}

\section{Erratum to: \\ J.H.P. Eloff et al. (Eds.) \\ Information Security Management \& Small Systems Security \\ DOI: $10.1007 / 978-0-387-35575-7$}

The book was inadvertently published with an incorrect name of the copyright holder. The name of the copyright holder for this book is: (c) IFIP International Federation for Information Processing. The book has been updated with the changes.

The updated original online version for this book can be found at DOI: $10.1007 / 978-0-387-35575-7$ 